NBER WORKING PAPER SERIES

\title{
POISONED GRAPES, MAD COWS AND PROTECTIONISM
}

\author{
Eduardo Engel
}

Working Paper 6959

http://www.nber.org/papers/w6959

\section{NATIONAL BUREAU OF ECONOMIC RESEARCH 1050 Massachusetts Avenue \\ Cambridge, MA 02138 \\ February 1999}

The author is grateful to Claudio Rammsy for outstanding research assistance, and to Alexander Galetovic, James Hines, and Anne Krueger for helpful comments and suggestions. Financial support from the Mellon Foundation (Grant 9608) is gratefully acknowledged. The views expressed here are those of the author and do not reflect those of the National Bureau of Economic Research.

(0) 1999 by Eduardo Engel. All rights reserved. Short sections of text, not to exceed two paragraphs, may be quoted without explicit permission provided that full credit, including ${ }^{\circledR}$ notice, is given to the source. 
Poisoned Grapes, Mad Cow, and Protectionism

Eduardo Engel

NBER Working Paper No. 6959

February 1999

JEL No. F13, F14, F15, Q17

\begin{abstract}
$\underline{\text { ABSTRACT }}$
This paper studies two episodes where an exporting industry saw its sales plummet after importing countries banned their products to protect their citizens' health. The first case is the poisoned grapes crisis involving Chile and the United States in 1989. The second is the mad cows dispute between the United Kingdom and the European Union in 1996. These case studies motivate a new definition of "protectionist measure" which is applied to argue the European Union's ban on British beef exports did not constitute a protectionist measure, while the US ban on Chilean fruit possibly classifies as such a measure.
\end{abstract}

Eduardo Engel

Stanford University

579 Serra Mall, Room 149

Stanford, CA 93405-6015

and NBER

emengel@leland.stanford.edu 


\section{Introduction}

An appropriate definition of the term "protectionist measure" is useful both for conceptual and practical purposes. From the conceptual standpoint, modeling the effects of the new faces of protectionism requires a definition of what constitutes a protectionist measure. From a practical point of view, having a framework to decide when a measure is protectionist facilitates the efficient operation of mechanisms for resolving trade disputes (both within multilateral organizations such as the World Trade Organization, and as part of free trade agreements such as NAFTA).

This paper proposes a new definition of "protectionist measure," whereby an action taken by a country is classified as protectionist when it differs from what would have been done by a planner considering the well being of all countries involved. Two case studies are presented to motivate this new definition. The first deals with the poisoned grapes crisis involving Chile and the United States in 1989. The second is the mad cows dispute between the United Kingdom and the European Union in 1996.

On March 13th 1989, the United States Food and Drug Administration (FDA) reported having found two grapes from Chile contaminated with cyanide. This led the FDA, without prior consultation with the Chilean government, to apply a ban on Chilean fruit, thereby setting off the so-called "poisoned grapes crisis," which struck at one of the main pillars of the Chilean export model. Four days later, following hard bargaining between government representatives from Chile and the United States, and the signing of agreements on strict sanitary controls, the United States announced an end to the embargo. In the meantime, the economic damage caused to Chile amounted to more than US $\$ 400$ million. Section 2 describes this case in detail.

On March 27th 1996, the European Union imposed a worldwide ban on beef exports from the United Kingdom, thereby setting off the so-called "mad cows crisis." Recent scientific evidence had suggested that the possibility of mad cow disease causing fatal encephalopathies in humans could not be ruled out. Section 3 describes the "mad cows" story.

The main purpose of these two embargoes was to safeguard people's health, so it could be argued that calling the measures 'protectionist' is incorrect. In Section 4 we argue that the new definition of "protectionist measure" proposed in this paper implies that one of the bans cannot be classified as protectionist, whereas the other could be. Finally, Section 5 presents the paper's main conclusions. The reader who recalls the main events associated with both cases may pass directly 
to Section 4 where the paper's main thesis is presented.

\section{The poisoned grape crisis $^{2}$}

\subsection{The March crisis}

\subsubsection{The embargo}

On Monday March 13th 1989, the United States Food and Drug Administration (FDA) announced it had found two grapes originating in Chile contaminated with cyanide. Although the dose was not lethal, the FDA used a press release, broadcast throughout the country, to announce a quarantine on fruit from Chile on its way to the United States market, and made a public call to withdraw it from the shops and not consume it. This measure not only affected half of that season's production from Chile, which was being loaded for shipment or on its way to the United States, but it also affected Chilean fruit that had already entered the USA and was being kept in commercial distriputor's refrigerators or warehouses, and whose destruction was being recommended. The FDA's decision to ban Chilean fruit and publicize the measure through a press conference broadcast throughout the United States, generated a veritable panic among consumers. A few hours after the announcement by the FDA commissioner, Dr. Frank Young, the main supermarket chains had already taken all Chilean fruit off their shelves. The ban on Chilean fruit due to the discovery of cyanide-infected grapes was the main item on news programs on all the television networks and in the written press nationwide.

Press accounts after the event revealed that, during the week leading up to the announcement, the United States embassy in Santiago had received several telephone calls threatening to contaminate fruit destined to the North American and Japanese markets. This had led to an initial restriction on the entry of Chilean fruit, which was lifted a few days later following exhaustive checks yielding no positive results, and in view of the "notable safety measures adopted in Chile," as was acknowledged by the US government. These precautionary measures were known only by authorities from both countries and Chilean exporters, and did not reach public opinion.

\footnotetext{
${ }^{2}$ The information on which this section is based is taken from press reports. The main sources are cited in the footnotes.
} 
Later, in response to a second anonymous call, FDA checks were stepped up, with more than 100 officials being deployed to inspect and check, at the exporters' expense, approximately $10 \%$ of the 600,000 boxes of Chilean fruit arriving daily at US ports. On the morning of March 12th, FDA inspectors checking the cargo of the "Almería Star," containing part of the production of exporter Julia Saavedra of Curacaví, Chile, found two grapes in a box of grapes of the Flame Seedless "Crispy" variety, that showed signs of having been injected. The grapes were discolored and had a ring of crystalline material surrounding a presumed pinprick. Laboratory analysis confirmed the presence of cyanide, although in a dose that was not lethal for human beings. Due to its high volatility in an acid medium such as a grape, it was not possible to determine the size of the dose originally injected.

In Chile the measure caused a huge public outcry, due to the economic damage foreseen. Share prices fell immediately, with shipping company stocks the most affected, dropping $10.7 \%$.

The United States ban on Chilean fruit immediately affected not only the producers but also the long chain throughout the flourishing fruit export industry. But more serious still was the damage caused to foreign consumers' confidence in Chilean fruit. A measure announced in such a spectacular way not only threatened immediate economic losses, but the closure of markets that were becoming increasingly sensitive to the presence of chemical products in food.

That same Monday 13th, Chilean Interior Minister, Carlos Cáceres, addressed the country over the radio and TV networks, stating that while he did not support the decision taken by the USA, he did understand their concern for the health of their consumers. He expressed confidence that a solution to the problem would be found. He also denounced the event as a terrorist attack supported by the Communist Party and announced an investigation to find the guilty parties. At the same time he announced a strengthening of security measures in the whole process of fruit production, from the moment of harvest until its arrival at the port of destination.

The government of General Pinochet set up a crisis committee comprising the Ministers of the Interior, the Government, Foreign Relations, Agriculture, Finance and the Presidency, which operated permanently throughout the critical days that followed with the job of drawing up strategies to deal with the emergency.

The military government's immediate response pointed in three directions at the same time. In the first place, the Foreign and Agriculture Ministries moved rapidly to set up negotiations at the highest level in the US, aimed at obtaining a speedy reversal of the measure. For this purpose an 
official committee traveled the next day to Washington, where it embarked upon an active agenda of contacts with congressmen, business leaders and US government officials, whom they informed about the effects the measures would have, as well as the safeguards adopted by Chile to protect its exports.

In the second place, sanitary controls were tightened, and an investigation was begun to find the perpetrators of the contamination, with a lawsuit being filed in the courts for infringement of the Internal State Security Act.

Lastly, studies were commissioned to assess the impact of the measure on the export sector and the national economy as a whole, and to define possible measures to support the sector.

Once in the United States, the government delegation headed by Foreign Minister Errázuriz made contact with other US authorities, as well as industry representatives and members of Congress. In a press conference Senator Heinz ${ }^{3}$ drew attention to the urgent need to find a rapid solution, in view of the damage being caused to Chilean and United States interests. He argued before the FDA in favor of a plan to allow confidence be totally restored in the many fruit and vegetable products received from Chile.

Three days after the ban was imposed, Secretary of State James Baker, met with the Chilean Foreign and Agriculture Ministers, agreeing to work together with them to find a solution to the critical situation affecting Chilean fruit exports. It was announced that a team of FDA experts would travel to Santiago to verify measures of control and security in shipments, and in response to stories in the Chilean press claiming a political origin to the FDA measure, Baker declared that the action "has not been taken, in any way, on political considerations: it has been taken, strictly, for safety and health reasons." He added that not only were Chilean producers being hurt by the measure but so too were the citizens and interests of the United States.

The Chilean Agriculture Minister and the FDA Commissioner reached an agreement for a solution to the crisis, for which Chilean and United States technical experts began to draw up the details. On Friday March 17th, four days after the embargo and after hard negotiations and agreements on strict sanitary controls, the resumption of fruit shipments from Chile was announced in the United States as from March 21st.

\footnotetext{
${ }^{3}$ Representative of the State of Pennsylvania where the port of Philadelphia is located.
} 


\subsubsection{The reaction in Chile}

As far as the military government was concerned, the contamination of the grapes was a terrorist act of clearly Marxist origin. Thus, on March 16th the Secretary General of the Government, Minister Miguel Angel Poduje, denounced the existence of a "Fruit Plan" set up by the Communist Party, aimed at sabotaging Chilean fruit exports. The Agriculture Minister blamed the attack on the Communist Party and the opposition, linking the ban to the boycott being promoted by the CUT (Unitary Association of Worker Unions) and United States worker organizations such as the AFL-CIO, ${ }^{4}$ while the head of the navy, Admiral Merino, described it as "one of the many low blows the United States has hit us with." The decision to suspend the entry of Chilean fruit into the United States market was "a malicious act intended as an attack on Chile, that has been cooked up here by the Communists," he declared..$^{5}$ The only government authority who showed a more cautious attitude was Foreign Affairs Minister Errázuriz. What mattered for him was to resolve the crisis and avoid opening up new fronts of conflict with the US. Criticism of the US government centered on having taken the decision to impose the ban with no prior consultation, an attitude which was seen as inconsistent with a trading-partner relationship.

The coalition of political parties opposing Pinochet grouped in the "Concertación de Partidos por la Democracia" declared that the ban was a precipitous measure which bore no relation to the limited dimension of the risk being alleged.

The politician Luis Maira, who at the time led a coalition of parties to the left of the Concetacion, speculated that the embargo was a consequence of the unsatisfactory solution to the Letelier case. ${ }^{6}$ Communist Party leaders for their part requested the appointment of an investigating judge to investigate the case, and clarify the military government's accusations against it.

\subsubsection{Economic effects of the embargo}

The FDA embargo came at the peak moment of the export season, when $45 \%$ of the fruit had left the country. It was also the moment of the agricultural sector's greatest indebtedness. The Superintendency of Banks stated that when the ban was announced export-sector debts with private

\footnotetext{
${ }^{4}$ El Mercurio, March 15, 1989.

${ }^{5}$ La Segunda, March 14, 1989.

${ }^{6}$ Orlando Letelier, Foreign Relations Minister under President Allende, was killed in a car bombing in Washington, D.C., in 1976.
} 
local banks were bordering on US $\$ 400$ million.

Despite the short duration of the ban (just four days), the economic effects for the country, as well as for the whole chain of agents involved in the fruit export business, were considerable. The Chilean Congress' Report on the Grapes Case agreed with exporters' estimation of private sector losses, put at about US\$330 million. These losses forced the military government to take steps to support producers and exporters. To alleviate the damage caused by the ban and prevent the collapse of the sector, on March 19th General Pinochet announced a project to compensate and provide special credit lines for the producers and exporters that had been harmed. The set of measures introduced by the military government to bail out the export sector also included a mechanism of external debt capitalization, through which exporters acquired Chilean external aebt paper abroad, which was traciing at $60 \%$ ố its nomina: vaiue, and the Centra: Bank ố Cnile bought it back at par. Meanwhile, the Association of Banks together with the exporters, signed an agreement allowing for the rollover of financial liabilities falling due between March 13th and June 30 th that year.

According to the Congressional Report of the Chamber of Deputies of Chile, the cost to the Treasury of the measures adopted amounted to US\$198.2 million, ${ }^{7}$ while a Central Bank report stated that US $\$ 263$ million from the Copper Stabilization Fund were used to alleviate the crisis. ${ }^{8}$

\subsection{New revelations and investigations into the case}

\subsubsection{Accusations and new information}

Following the lifting of the embargo by the US Government, both the Chilean and US press began to reveal new information relating to the case, putting forward a series of allegations and raising suspicions against those who took the measures in the United States.

As a possible explanation for the excessive zeal with which the FDA acted, supported by the White House, some United States newspapers pointed to the bitter experience of the Bush administration in December 1988, when it received a threat of a bomb on a Pan Am aircraft over Scotland. On that occasion no precautionary measures were taken, and the aircraft blew up in the

\footnotetext{
${ }^{7}$ Report of the Investigating Committee, pp. 56-63.

${ }^{8}$ See Basch and Engel (1993) for a description of the Copper Stabilization Fund. Although the report does not say where this sum went, most likely it helped finance the purchase of external debt promissory notes by the Central Bank.
} 
air killing 207 people. Dr. Young acknowledged that this event had influenced his decision. ${ }^{9}$

In July 1989, four months after the embargo, Herb Denenberg, a journalist at the CBS network, started a series of three reports for the Channel 10 news network in Philadelphia on the case of the poisoned grapes. After two months of investigation with a team of experts, he called into question the supposed poisoning of the grapes, arguing that FDA analyses had not been conclusive and suffered from numerous defects which violated their own procedural norms.

On November 16th 1989, the Wall Street Journal published an extensive report by journalist Bruce Ingersoll, presenting evidence that strongly suggested that the poisoning of the fruit had occurred in the US and not in Chile.

Chilean and US experts pointed out the impossibility of the grapes having been contaminated in Chile or that they could have been injected with cyanide. Some specialists raised a series of questions about the "miraculous" way in which the two contaminated grapes were located in a shipment of millions of bunches of grapes sent to the United States. Herman Chernoff, for example, a renowned statistics professor at Harvard University, argued that the fact that there were a large number of boxes from the vineyards of Julia Saavedra among the boxes inspected, despite the fact that just 26 of the 4045 pallets in the "Almería Star" came from this vineyard, suggested the FDA had information on where to look for the contaminated grapes: the probability of Mrs. Saavedra's vineyards being over-represented in this way in a random sample was less than one in ten thousand. ${ }^{10}$ Lastly, criticisms were also made of the disproportionately stark measure taken by US authorities, namely a ban on all exports, compared with the insignificant quantity of poison discovered. The measure was adopted without weighing up the disastrous economic consequences for Chile. It was pointed out that in response to more serious cases, the FDA had never before taken such a drastic step.

\subsubsection{Investigations into the grapes case}

On February 27th 1990 the prosecuting judge in charge of the investigation into the possible poisoning of the grapes in Chile, provisionally dismissed the case having found no evidence to indicate who contaminated the grapes. There were also reports of a lack of collaboration from the US authorities in reply to judicial entreaties.

\footnotetext{
${ }^{9}$ El Mencurio, March 26, 1989.

${ }^{10}$ The Wall Street Journal, November 16th, 1989.
} 
In June 1990 the Association of Chilean Exporters published a detailed report of the result of laboratory studies which concluded that the grapes were contaminated in the FDA laboratory in Philadelphia.

On January 24th 1991 the Chilean Chamber of Deputies approved the report of the Special Commission looking into the case. To date, this is the only public document released by a regular Chilean state agency related to the case. It is also the one official document that brings together all the public and private reports and testimony existing on the issue so far. After relating in detail the events giving rise to the ban, the Commission analyzed the legal responsibilities of the US government, concluding that there was manifest bad faith in facing up to the situation. The report argues-considering the numerous laboratory reports and testimonies by experts - that the contamination did not occur in Chile. In this regard it draws attention to a series of facts which demonstrate a total non-compliance with the legal rules and procedures that should have been followed in response to the contamination: "... it can be stated, with some degree of certainty, [...] that the FDA had prior knowledge about the location of the contaminated grapes," so that when the ship with the identified cargo arrived, it was inspected in such a way as to enable the contaminated grapes to be found.

In the light of this and other pieces of information, the Commission concluded that the contamination could not have been carried out in Chile or on the way to the US. Given the characteristics of the poison, the difficulties of injecting cyanide into individual grapes, as well as a series of anomalies in the FDA procedures, contamination a few hours before inspection, possibly in the FDA laboratories, can be put forward as the most likely explanation.

\subsubsection{The pursuit of United States compensation}

As from 1990, the new coalition government of the Concertacion, together with fruit exporters and producers, concentrated their energies on obtaining compensation from the US government for the economic losses the event had meant for Chile. This action was backed up by the numerous examples of irregularity and negligence which, in the view of the Government and exporters, FDA officials had committed when taking their decision, as well as the conviction that the fruit had been contaminated outside Chile.

After studying various courses of action, on February 28th 1991, the government of President 
Aylwin and the exporters initiated separate administrative and legal actions (for US\$246 and US\$212 million respectively) against the FDA for the material damage caused by the United States measure.

In August of that year the FDA rejected the Chilean claims. Later in February 1992, the private sector filed a lawsuit in the Federal Court of the District of Philadelphia. The United States government appealed to "the governments jurisdictional immunity" to reject judicial action against it. On December 30th 1992, the court's preliminary ruling came down against the Chilean demand. In view of the latter, and after studying the possible alternatives, on March 30th 1993 the Aylwin government invited its US counterpart to take the case to the 1914 Bryan-Suárez Mujica Treaty, to resolve their differences. ${ }^{11}$ Three months later the United States rejected the Chilean request, proposing as an alternative the use of diplomatic channels and the formation of a binational working party. The Chilean government accepted this proposal, and initiated a process of negotiation that concluded in February 1994 proposing the establishment of a series of tariff compensations to favor Chilean exports. These measures were rejected by the producers and the exporters, and were described by the government of President Frei as insufficient. Thus the work of the binational commission came to a halt.

Simultaneously, lawyers for the Chilean producers appealed the initial ruling in the Appeals Court of Philadelphia, obtaining their first judicial victory (February 25th 1994), which in turn was appealed against by the United States government. At the end of 1995, the United States Supreme Court ruled definitively on the case, rejecting the Chilean petitions to bring the US administration to trial for the ban. In response to this, Chile's Foreign Minister appointed ambassador Fabio Vio to coordinate an ad hoc commission to draw up a report on the possible courses of action Chile could take. This commission recommended using the diplomatic route. To this day the case remains unresolved, being one of the main pending problems in Chilean-US relations.

\subsection{What was the origin of the embargo?}

To understand the origin of this crisis two questions have to be answered. First: who contaminated the two grapes found by the FDA that Monday March the 13th? Secondly: assuming the FDA acted in good faith, why, once the grapes had been found, did the Bush administration decide to

\footnotetext{
${ }^{11}$ This treaty provides a mechanism for dispute resolution between both countries. It can be applied only when both countries invoke it.
} 
apply so drastic a measure, with its grave economic consequences for Chile?

As regards who contaminated the grapes and why, there are three main hypotheses. First there is the conspiracy and sabotage theory that various public figures and sectors have insistently sustained. The new facts that have come to light seem to paint a picture that lends credence to the existence of a political objective behind the FDA decision. What might this have been? Some people point toward intimidating General Pinochet not to modify the established itinerary towards democratic transition following his defeat in the 1988 plebiscite. According to this version of events, the US government may have been concerned about possible attempts by Pinochet to keep himself in power illegitimately, so a plan was set up to put pressure on a highly sensitive area of the Chilean economic model. A less conspirational version of this hypothesis is represented by the view of Luis Maira who, as was mentioned above, argued that the measure could be a response to the military government's total lack of interest in resolving the Letelier case.

Secondly, there is the protectionist hypothesis, according to which the embargo responded to strong pressures being exerted on the United States Congress by California producers seeking to protect themselves against growing competition from Chilean fruit. Despite this type of hypothesis being discounted in official Chilean circles, there are elements to suggest a degree of collusion between the State Department, US health agencies and the US Congress to restrict the entry of Chilean fruit. A controversial telex sent by the Secretary of State to countries importing Chilean fruit shortly after the crisis erupted, as well as the curious behavior by the US agricultural attache in Saudi Arabia, who contacted importers in that country to persuade them to cancel contracts with Chilean exporters, ${ }^{12}$ lend some support to this hypothesis. However, the protectionist hypothesis is not convincing because the Chilean grape export season does not overlap with grape production in California. Furthermore, neither Chilean nor North American producers can significantly prolong their export seasons, so potential competition between producers in the two countries in the future cannot be invoked either. Sustaining this hypothesis, therefore, requires irrational behavior on the part of agricultural producers in California.

A third hypothesis points to negligence by the FDA. Numerous anomalies and unanswered questions make it plausible to imagine that, acting under pressure in an atmosphere where the FDA was already testing the effects of cyanide in fruit in response to telephone threats received in Santiago, it could have made mistakes or acted negligently, thereby causing the contamination. Thus for

\footnotetext{
${ }^{12}$ La Segunda, July 16th, 1989.
} 
example, according to this hypothesis one cannot rule out the possibility that the contaminated grapes formed part of experiments the FDA was carrying out and that they got mixed up with other grapes that were being examined for preventive reasons.

Next we consider whether the FDA, if not responsible for the actual poisoning, could be held responsible for proposing a disproportionate measure causing significant damage to the Chilean economy. What might explain this type of attitude? Elements singled out by the press at the time include the weak position of Commissioner Young, the lesson of the attack on the Pan Am aircraft, and pressures from consumer organizations due to the failure to ban apples with "Alar." 13 Nor can one discard the possibility that the FDA had agreed to take part in a political operation mounted inside the federal government.

Finally, it is worth considering the possibility that Commissioner Young acted rationally in deciding to apply the embargo. To this purpose the situation he faced when the contaminated grapes were discovered has to be analyzed. When doing so one cannot assume he was aware of information that became available months, or even hours after he made his decision. Obviously this analysis assumes Young did not participate in any plot. When news of the discovery of two contaminated grapes broke on Monday March 13th, how must Commissioner Young have reasoned? Section 4 argues that this last alternative is the most convincing, and that any official in the post of FDA Commissioner would have acted in the same way. However, this does not contradict the fact, as also argued in that section, that the measure taken by Commissioner Young can be classified as protectionist.

\section{The case of the $\operatorname{mad}$ cows $^{14}$}

\subsection{The embargo}

On March 27th 1996 the European Union (EU) imposed a worldwide ban on beef exports from the United Kingdom, giving rise to the so-called "mad cow crisis." In 1995 exports of British beef and its side-products amounted to US\$1 billion.

Just one week earlier the UK Agriculture and Health ministers had assured the House of Com-

\footnotetext{
13 "Alar" is a chemical product harmful to health.

${ }^{14}$ The information sources for this section were press agency dispatches and articles from The Economist.
} 
mons that eating British beef did not involve any risk: Health Minister Stephen Dorrell stated that the risk of contracting Creutzfeldt-Jakob Disease by eating beef was "very low" and he would continue eating it. However, after years of assuring its citizens that there was no connection whatsoever between eating beef and contracting the brain disease referred to, the ministers' declarations served little purpose.

By making their statement, the British ministers had anticipated a press conference which a government commission of scientists, set up to study the relation between mad cow disease and brain illnesses in humans, were about to hold. In this press conference new scientific evidence would be announced indicating that "bovine spongiform encephalopathy"-mad cow disease as is commonly known - could be transmitted to human beings. They stated that there was no evidence that this had indeed occurred, but the mere fact that it was possible was extremely worrying,

Beef sales plummeted throughout the European Union. In the United Kingdom beef cattle sales fell in nearly $90 \%$ the week after the declaration of the ban. Two weeks after the announcement, beef prices had fallen between 20 and $50 \%$ in the countries of the European Union. Sales volumes had dropped even further: consumption fell $50 \%$ in Belgium, $30 \%$ in France, $50 \%$ in Portugal and $60 \%$ in Italy. In Germany, where there had long been concern among consumers about mad cow disease, beef sales came to a nearly total halt. European export markets also were threatened. Countries such as Ghana and Libya banned imports of all European beef, regardless of whether it was British or not.

\subsection{Background}

Bovine Spongiform Encephalopathy (BSE) belongs to the group of degenerative illnesses that attack animals' brains. The human equivalent is the Creutzfeldt-Jakob Disease (CJD), an extremely rare illness that affects an average of one person in a million, attacking especially old people. One famous victim of CJD was George Balanchine, the well known Russian choreographer who died of the illness at the age of 79 .

During the past decade 160,000 cases of BSE were detected in British cattle, a much higher number than in any other country in the world; the next country being Switzerland with 206 cases. In fact, just $0.3 \%$ of BSE cases have been in non-British cows. The British cattle probably contracted the disease by eating fodder made from brain, spinal cord and other sheep derivatives 
(BSE hides in the central nervous system). Sheep suffer from an illness which is a cousin of BSE, known as "scrapie," a disease which for centuries has wreaked death among sheep and goats.

The first case of BSE occurred in England in 1986. In 1988 when the fields of Britain were full of mad cows, the government prohibited using fodder based on dead animals (goats and sheep as well as cattle); it also gave a warning of the possible dangers involved in people eating viscera from these animals. Meanwhile, it went on insisting that there was no relation whatsoever between BSE and CJD.

However, the manner in which the British government adopted these measures was inept. Among the mistakes it made in its handling of the BSE epidemic at the end of the 1980s, at least four are worth mentioning. Firstly it only paid half the market value for infected cattle, and this probably led many farmers to take their infected cattle to the slaughterhouses as quickly as possible, rather than sell them to the government.

A second error was to only gradually increase the enforcement of measures to prevent cows belonging to herds with outbreaks of BSE from reaching the food chain. The same happened with measures to avoid contamination in slaughterhouses. The third mistake made by the British government was to keep on insisting for a long time that there was no risk at all. An extreme example was Agriculture Minister, John Gummer, who gave a hamburger to his four-year old daughter in front of the television cameras.

A fourth mistake made by the British government was to allow British slaughterhouses during the 1980s to render down animal carcasses at very low temperatures, frequently below 100 degrees centigrade, whereby potential sources of infection were not completely destroyed. And this despite the fact that a commission of British experts had suggested raising temperatures at the beginning of the 1980s. Other countries demanded much higher temperatures.

Thus, one possible explanation of why the BSE epidemic broke out in the United Kingdom is that (a) this country is one of the few countries that simultaneously has a large number of cattle and sheep; (b) historically the United Kingdom has had a much greater number of scrapie cases among its sheep than any other country; and (c) temperatures for rendering down cattle carcasses in the UK were considerably lower than in other countries during the 1980s. 


\subsection{New scientific evidence}

The evidence that led British scientists to argue for the possible existence of a connection between BSE and CJD was the appearance of a new variant of CJD in the United Kingdom. Robert Will, director of the panel on Creutzfeldt-Jakob Disease in the University of Edinburgh, and a member of the government panel, identified "an unknown and consistent pattern" of the disease in ten victims with CJD-type symptoms. None of the victims seemed to have had the genetic deficiencies commonly associated with the illness. Even more worrying was the fact that the average age of those ill was 27 years; all were under 42 . Until this group was identified, the average age of those sick with CJD was 63 . The type of damage to the brain, the initial symptoms of the illness and the duration of the disease were all different from earlier cases.

All this led scientists to conclude that, in the absence of a better explanation, the possibility existed that these cases had contracted the disease from infected beef. There was no demonstration that indeed this was so, and it was possible that the new variant of the illness had been found in the United Kingdom simply because British scientists were studying the disease much more assiduously than their peers in other countries.

There was great uncertainty about how many British people were incubating the new variant of CJD if the cattle population infected with BSE really was responsible. Even if the transmission of the disease from cows to humans was difficult, millions of British people could have been exposed to cows infected with BSE before 1988, the year in which the British government introduced measures to eradicate contaminated cattle and prohibited the use of brains and spinal cords in products for human consumption. Even though the number of CJD cases is small, the disease's long incubation period-put at between five and ten years - makes it difficult to predict what will happen. John Pattison, director of the government consultative committee ventured the opinion that "it could indeed be a question of a large-scale epidemic." Another scientist estimated the number of British deaths that could occur in the future as "between 500 and 500,000 per year," which only reflected scientists' almost total ignorance on the issue. 


\subsection{John Major vs. the European Union}

The real problem facing the British government was in weighing the costs of alternative measures against their potential benefits, in a situation characterized by great uncertainty which was hard to quantify.

When the British ministers informed the House of Commons of the possibility of a link between BSE and CJD, they committed a serious error from the political point of view, "by entering a room without the slightest idea of whether there was a way out." A few days later they could be seen desperately seeking an escape route.

A basic solution needed two key questions to be answered: firstly, how many people were infected by the human version of BSE during the 1980s, before the British took measures to prevent suspicious material entering the food chain? Secondly, is there any risk in eating beef today?

As regards the first question, the British government said virtually nothing during the initial months following the ban, but then there was little they could say to calm the population.

As to whether sufficient measures had been taken to protect people who eat beef at the present time, the biggest risk lay in non-compliance with the rules imposed at the end of the $1980 \mathrm{~s}$, or that infected animals that were not showing visible symptoms might reach the slaughterhouses. The solution to the first problem was to increase supervision, but it would be impossible to prevent the second problem from occurring unless the entire beef cattle population were slaughtered, since certainly there were cows carrying the disease in a state of incubation. However, it was clear that the number of individuals incubating CJD from these causes was a tiny fraction of those who were infected before 1988 .

The British government's initial strategy to get the European Union to lift the embargo was to deny that there was a problem. There was talk of a hysterical reaction on the part of their European partners and a plot to strike a blow against the efficient English beef export industry. This strategy, if it can be called such, produced few results. The British government's frustration became clear almost a month after the embargo was declared, when British Primer Minister John Major referred to the European ministers as "a bloody bunch of shits." 15

From the outset, the European Union made it clear that it would share the cost of any solution to the mad cow crisis. There was a precedent for this in the $70 \%$ of the costs that the EU assumed

\footnotetext{
${ }^{15}$ The Economist, April 27, 1996.
} 
when Germany had faced an outbreak of swine fever. Although the United Kingdom had initially sought compensation of $80 \%$ of the cost of any animal cull (which is somewhat ironic in view of the fact that the British government at that time thought assuming $70 \%$ of the costs in the German case to be excessive), the government swiftly agreed that Britain would pay $30 \%$ and the EU the remaining $70 \%$.

Reaching agreement on the actions the UK would have to undertake for the ban to be lifted was considerably more difficult than sharing out the cost of any measures. On April 16th, British Agriculture Minister, Douglas Hogg, announced a packet of measures at the minimalist end of the spectrum of possibilities. Measures would be taken for cows older than 30 months to be kept out of the food chain after being slaughtered, and supervision would be tightened on the provisions adopted at the end of the 1980s. The policy was designed more at the behest of meat producers than of consumers. Meat from herds that had been infected with BSE continued to be sold. The measures proposed by the United Kingdom were not enough to satisfy their European partners.

Eventually the British government began to consider taking a series of reprisals on its European partners. This idea divided Primer Minister Major's party between the pro- and the anti-Europeans, due to the effects this type of policy would have on relations between the United Kingdom and the rest of the EU. The conservative daily newspaper The Daily Telegraph proposed invoking a legal loophole to prohibit imports of French cheese and apples. Others suggested that the UK should ban beef imports from the European continent where there had also been cases of BSE. There was also talk of the United Kingdom using its right of veto to paralyze the EU, or that it would refuse to pay its contributions to the community budget.

To eurosceptics who saw the ban as a plot to damage the efficient British beef industry, those on the continent replied that their markets were suffering as much or more than the British market. At the end of April German consumption remained below half its level prior to the ban. Throughout the EU consumption was down by $30 \%$, and in the United Kingdom there was a similar fall (one third).

On April 23rd, 66 members of the British Parliament belonging to the eurosceptic wing of the ruling Tory party, voted in favor of a motion to exempt Great Britain from the decisions of the European Court of Justice, a motion that, if approved, would force the United Kingdom to abandon the EU.

In the end, the idea prevailed among the British Government of taking retaliatory action against 
the EU to the limits of legality. On May 22nd, the British embassy in the EU announced the start of a blockade on community activities in meetings of the permanent representatives who briefed the Council of Ministers of the European Union. This meant blocking all decisions that required unanimous approval.

"The Prime Minister hopes that there will be an agreement at the Florence Summit for a partial lifting of the ban on beef products and a definite timetable for lifting the general embargo. In the meantime, the United Kingdom's capacity to cooperate in European Union matters is impaired," stated a terse announcement from London.

The declarations reacting to the policy of British non-cooperation indicated that a solution would be negotiated before the EU summit in Florence on June 20th and 21st. If the impasse was not resolved before this meeting, the European partners would begin to "retaliate against the British" according to an announcement by European Commission President Jacques Santer.

On Monday June 3rd, six of the 15 EU member states meeting in Luxembourg ruled out any lifting of the ban on exports of gelatin, tallow and semen from British cattle. Germany, Austria, Portugal, Holland, Belgium and Luxembourg all opposed making the embargo more flexible, thereby preventing a qualified majority being formed as needed to take this type of decision. The European Commission now had only a fortnight to adopt a decision that would satisfy the British. In the meantime, the rest of the EU's exasperation with the United Kingdom became clear: on June 9th European Commission President, Jacques Santer, told the British newspaper The Observer that "the EU is reaching a moment of truth. We are getting to the limit of our tolerance."

By mid-June signs of compromise became apparent. The UK presented a new plan for lifting the export ban and relaxing its veto on EU decisions. Meanwhile, 70 members of the British Parliament, nearly half of the backbench votes of the government party, voted in favor of a motion to hold a referendum on British membership of the EU, using a clearly loaded question.

On June 18th the community executive approved a document prepared by European Agriculture Commissioner, Franz Fischler of Austria, setting prior conditions on the UK for a start to lifting the ban. These included a requirement to mark all beef cattle herds and a ban on using cattle, sheep or goat offal in animal feed. In addition, it included incinerating all cows on completion of their productive life at 30 months of age and a selective cull involving more than 100,000 head of cattle.

The Commission declared that it did not accept the British demand to lift the embargo on 
its exports to third countries, as it considered that authorization of British beef exports to third countries could only be given once the ban had been lifted on these products within the European Community.

On June 19th the European Commission approved the British plan to control mad cow disease. The European Commission President, Jacques Santer, declared himself satisfied with the European Veterinary Committee's decision to approve the British plan of sanitary measures, and the London plan was endorsed unanimously after twelve hours of discussion. The motion approved immediately ended the embargo on exports of gelatin, tallow and semen from British cattle and involved a gradual lifting of the embargo on the export of other derivatives as well as British beef itself.

Apart from incineration of several million head of cattle on completion of their active life, the plan included the culling of about 100 thousand animals born between 1989 and 1990 which were still active in the reproductive cycle. It also involved an effective program of cattle identification, as well as control measures to exclude meal of animal origin in beef cattle feed. At the same time, the United Kingdom announced an end to its non-cooperation policy, whereby more than 90 issues being dealt with in the EU had been blocked.

\section{Lessons and a definition of protectionism}

\subsection{Comparison of the two case studies}

Following the declaration of the two embargoes, both Chile and the UK took immediate steps aimed at eliminating risks to consumers. In each case situations of great uncertainty were faced which, in turn, were difficult to quantify. Were there more contaminated grapes out there, and if so how many? How many British citizens were incubating CJD? Might the beef that British people were currently eating be contaminated with BSE? Chile increased its phytosanitary controls whereas the United Kingdom tightened supervision of sanitary measures adopted at the end of the 1980s.

What stands out when comparing the two case studies is the striking difference between the negotiating power of Chile and the United Kingdom. The weakness of the Chilean bargaining position is evident. Thus, while the United Kingdom implemented a non-cooperation stance in the European Union, boycotting a good part of the Union's work for several weeks, it took three 
days after the declaration of the FDA ban for the Chilean delegation to be received by a highlevel government authority in the United States (Secretary of State, James Baker). Also the US authorities have systematically refused to collaborate with entreaties from the Chilean judicial system, and the Chilean government has had little success with its judicial claims against the US government, which successfully appealed on the grounds of "jurisdictional immunity of the government," subsequently refusing to invoke the 1914 Bryan-Suárez Mujica Treaty to resolve the conflict.

The European Union's offer to pay for $70 \%$ of a selective cattle cull contrasts with the fact that Chile has still not received any compensation from the US, almost a decade after the grapes crises. Furthermore, the year after the grapes crisis, when evidence pointing to at least some degree of negligence on the part of the FDA become known, the US Senate rejected legislation aimed at establishing equality of conditions in the inspection of Chilean fruit, and approved an extension of the marketing order on kiwis, plums, nectarines and apples imported into the United States.

\subsection{The decision by Commissioner Young}

It has been widely argued in Chile that the measure taken by the FDA was disproportionate, and that in more serious cases it had not adopted such draconian steps. To quote the report of the Chilean Chamber of Deputies, this was a "hasty and exaggerated measure" which caused serious economic damage to the country. "All of this allows one to conclude with considerable certainty that there was manifest bad faith on the part of the United States authorities in facing up to the situation" (p. 24 of the Report).

We argue below that Commissioner Young's behavior might have been justified given the incentives he was facing. In doing so, we put ourselves in the Commissioner's shoes, with the information he had available to him on March 13th 1989 when the poisoned grapes were discovered. We assume that Young did not participate in any plot against Chile, and we ask how he must have reasoned in deciding what measures to take.

A first possibility is that he conducted a cost-benefit analysis. What were the costs of ordering an embargo and what were the benefits? The benefits include the possibility of saving the lives of US citizens. The likelihood that some child might die from eating fruit injected with cyanide is small, but it is certainly not zero; if two grapes were found to be contaminated and there have been 
telephone threats in Santiago, one cannot rule out the possibility that there are more contaminated grapes on their way to the tables of US consumers. On top of this, one must consider the possible health effects from eating contaminated fruit, even if it does not have fatal consequences. What are the costs of an embargo? For US consumers there is the cost of not being able to consume Chilean fruit for a certain period of time, and having to pay a higher price for fruit imported from other countries, or for close substitutes to fresh fruit (e.g., canned fruit). However, there is a second cost that arises from imposing a ban: the enormous losses involved for Chilean producers. Yet, from Commissioner Young's point of view, this cost is practically irrelevant for his mission is to protect the health of United States citizens, it does not include considering the impact of the measures he takes on foreign producers. It is true that a ban also imposes costs on US firms (e.g., distributors of Chilean fruit), but these costs are much less than those faced by Chilean producers. The conclusion is that a cost-benefit analysis leads to imposing an embargo, without the need for any plot or conspiracy theory underpinning it.

There is a second course of analysis that Commissioner Young might have carried out, which also leads to imposing a ban. This is based on taking the measure that implies the least risk to his remaining in the high post he occupied. Thus, assuming the objective guiding the Commissioner, in deciding whether or not to apply the embargo was to avoid putting his job on the line, how would he have acted? When this type of analysis is carried out one has to weigh up the costs associated with the two possible misjudgements that he could make. The first is not to call for a ban and later it turns out that consumers get poisoned. The public's uproar would be large. Public opinion would conclude that Commissioner Young not only knew there might have been poisoned fruit, but also that he had learned nothing from the recent Pan Am airliner case. Most likely he would lose his job. The second misjudgment would be to declare an embargo when it is really not justified. The big losers in this case would be Chilean producers, who are not a threat to the FDA director's job stability. In so far as the available evidence was sufficient to have "reasonable doubts" about the safety of Chilean fruit, the advisable thing for Commissioner Young to do was to impose the ban.

It is worth contrasting the incentives that Commissioner Young faced, with those facing European Union Commissioner Fischler when he proposed the ban on British beef exports. Fischler does not work for any government in particular but is an official of the European Commission, for which reason he had to put community interests above the individual interests of its member countries. 
It is therefore not surprising that long before agreeing what measures the United Kingdom should take for the EU to approve a gradual lifting of the ban, they should have agreed on how to split the costs of any eventual measures. In the EU there were precedents set by analogous situations in which the EU had paid $70 \%$ of the costs; it was natural for a similar criteria to be adopted.

It is true that in the mad cows case there was tension between John Major's government and the EU regarding the measures to be taken, with Major embarking on a course of obstructionist actions that bordered on illegality. However, Major's behavior seems to have been determined more than anything else by political considerations within his party, rather than as a reaction to exaggerated demands by Britain's trading partners.

The conclusion is that the main difference between the situations faced by Commissioners Young and Fischler is that the former had almost no incentive to consider the welfare of the exporting country that would be affected by the ban being imposed, whereas the latter did have incentives to consider these effects.

\subsection{Relation to protectionism}

Were the measures adopted by the US against Chilean fruit or by the EU against British beef protectionist? We answer these questions in this subsection, and in doing so offer a new definition of what constitutes a protectionist measure.

There is no agreement regarding the best definition of what constitutes a "protectionist measure" or a non-tariff barrier to trade. The most general definition is credited to Walter (1972, quoted in Chambers and Pick, 1994), who defines it as any measure that distorts the volume of trade, the composition of the basket of goods traded between countries or the direction in which goods are traded. Using this definition, both the embargo imposed by the FDA and that applied by the EU would be protectionist measures. However, this definition is clearly too general. Indeed, any measure that legitimately sought to protect the health of a country's consumers by banning imports of a risky product would be protectionist.

A second definition is credited to Baldwin (1970, also quoted in Chambers and Pick, 1994). Baldwin focuses on the effect of a measure on the countries' real income and defines a non-tariff trade barrier as "any measure (public or private) which leads to internationally traded goods or services being allocated in such a way that potential real income is reduced at the global level." 
According to this definition, it seems natural to venture the opinion that the FDA ban constituted a protectionist measure, at least with the information available ex-post (there were no more poisoned grapes). In the case of the ban on British beef the situation is less obvious. Once the new evidence of a possible link between BSE and CJD became known, would global real income have been reduced to a lesser extent without the embargo?

The third definition of a non-tariff trade barrier comes from Hillman (1991, again quoted in Chambers and Pick, 1994). Hillman defines as protectionist "any decision or government practice, apart from the imposition of a tariff, which directly impedes the entry of imports into a country and/or discriminates against imports, i.e. a measure that is not applied equally to domestic producers or distributors."

The first half of the Hilman definition is similar to Walters, for which reason we only consider the second half. According to this part of the definition, neither embargo would constitute a protectionist measure, as in both cases it can be argued that the commissioners had information justifying the ban in question, so the measure was not discriminatory. To prove the contrary, one would have to show evidence of similar situations involving United States agricultural products, or those from European Union countries, where an embargo was not imposed.

The discussion in Subsection 4.2 motivates a new definition of a non-tariff trade barrier. Under this definition, a government measure that affects other countries can be classified as protectionist when it differs from that which a planner would have taken, considering the welfare of all the countries affected by the measure. ${ }^{16}$ Equivalently, a government measure is protectionist when, allowing for transfers between countries, there exists a Pareto superior alternative. For example, and working in partial equilibrium, a minimum quality standard is protectionist when it differs from the standard that maximizes the sum of the surpluses of producers and consumers from the country setting the standard, and from the country exporting the good targeted by the standard.

According to the definition given above, the ban on British meat does not satisfy the conditions to be classified as a protectionist measure. From the outset, the European Union knew that it would assume a significant part of the cost of any measures to be imposed. So there were incentives to impose a ban only if this would benefit the aggregate welfare of the union as a whole. Moreover, the case study of Section 3 does not provide evidence that the EU failed to act with the welfare of the union in mind.

\footnotetext{
${ }^{16}$ Of course, implicit is the assumption that the measure makes foreign countries worse off than they would be under the "world welfare maximizing" alternative.
} 
The ban on Chilean fruit is less clear. According to the above definition, one needs to know what Commissioner Young would have decided if he had had incentives to internalize the effects of a possible ban on the Chilean economy. It is not possible to give a clear-cut answer, but it is perfectly possible that he would have chosen to seek more information-e.g. by calling a meeting of scientists to assess the potential health risk of the contaminated grapes-before declaring an embargo. If so, the ban on Chilean fruit would satisfy the criteria to be classified as a protectionist measure.

\section{Conclusion}

One of the new faces of protectionism is that governments take trade measures to supposedly protect the health of their citizens without considering the disastrous effects these may have on the welfare of their trading partners. The ban imposed by the United States on Chilean fruit imports, discussed at length in Section 2, is an example of this type.

Due to the high degree of integration involved, the European Union provides a solution to this new form of protectionism among its member countries, as the case study of Section 3 illustrates. The decisions taken by the European Union regarding the mad cows case did adequately take account of the welfare of the affected exporting country (the United Kingdom).

The two case studies considered in this paper motivated a new definition of protectionist measure, whereby an action taken by a country (and affecting other countries) classifies as such when it differs from the measure that maximize the joint welfare of all countries involved. This definition can be extended in many directions. For example, Fischer and Serra (1996) apply it to the case of minimum quality standards and propose that when standards are imposed on goods with negative externalities in consumption, the welfare of foreign consumers should not be considered when deciding whether a measure is protectionist.

The analysis of the previous sections also brings out the importance of having mechanisms that provide incentives for those deciding to impose protectionist measures to internalize the cost that these measures impose on exporting countries. Ideally, if countries are obliged to assume the costs of the measures they impose, the resulting policies should improve the aggregate welfare of all 
countries involved. ${ }^{17}$ Using the definition of protectionism proposed at the end of Section 4, the result would be that with appropriate incentives, measures adopted would never be protectionist.

\section{References}

[1] Baldwin, R.E., (1970). Nontariff Distortions of International Trade. Washington, D.C.: The Brookings Institution.

[2] Basch, M., and E. Engel, (1993). "Temporary Shocks and Stabilization Mechanisms: The Chilean Case." Chapter 3 in Engel, E. and P. Meller (eds.) External Shocks and Stabilization Mechanisms, Washington, D.C.: Johns Hopkins.

[3] Chambers, R.G., and D.H. Pick, (1994): "Marketing Orders as Nontariff Trade Barriers", American Journal of Agricultural Economics, 76, 47-54.

[4] Fischer, R. and P. Serra, (1997): "Protection and Standards" (in Spanish). Chapter 3 in R. Fischer (ed.), The New Faces of Protectionism, Santiago: Dolmen.

[5] Hillman, J.S., (1991): Technical barriers to Agricultural Trade. Westview Press.

[6] Walter, I., (1972): “Nontariff Protection Among Industrial Countries: Some Preliminary Empirical Evidence," Economia Internazionale, 25, 335-54.

\footnotetext{
${ }^{17}$ Thus extending the "compensation principle" to international trade policy. It is worth discussing whether steps should be taken to ensure that compensation is effectively paid, so that the solution leads to a Pareto improvement at the country level. However, this goes far beyond the purpose of this paper.
} 